\title{
Distances from the deep plantar arch to the lesser metatarsals at risk during osteotomy: a fresh cadaveric study
}

\author{
Ichiro Tonogai ${ }^{*}$, Fumio Hayashi ${ }^{1},{\text { Yoshihiro } \text { Tsuruo }^{2} \text { and Koichi Sairyo }}^{1}$
}

\begin{abstract}
Background: The deep plantar arch is formed by anastomosis of the lateral and deep plantar arteries. Osteotomy of the lesser metatarsals is often used to treat metatarsalgia and forefoot deformity. Although it is known that some blood vessels supplying the lesser metatarsals are prone to damage during osteotomy, there is little information on the distances between the deep plantar arch and the three lesser metatarsals. The aims of this study were to identify the distances between the deep plantar arch and the lesser metatarsals and to determine how osteotomy could damage the arch.

Methods: Enhanced computed tomography scans of 20 fresh cadaveric feet (male, $n=10$; female, $\mathrm{n}=10$; mean age 78.6 years at the time of death) were assessed. The specimens were injected with barium via the external iliac artery, and the distance from the deep plantar arch to each lesser metatarsal was measured on axial and sagittal images.

Results: The shortest distances from the deep plantar arch to the second, third, and fourth metatarsals in the axial plane were $0.5,2.2$, and $2.8 \mathrm{~mm}$, respectively. The shortest distances from the distal epiphysis to a line passing through the deep plantar arch perpendicular to the longitudinal axis of the lesser metatarsal in the sagittal plane were 47.0, 45.7 , and $46.4 \mathrm{~mm}$, respectively, and those from the tarsometatarsal joint were 23.0, 21.0, and $18.6 \mathrm{~mm}$. The deep plantar arch ran at the level of the middle third, within the proximal portion of this third in 11/20 (55.0\%), 7/20 (35.0\%), and 5/16 (31.2\%) specimens, respectively, and at the level of the proximal third in 9/20 (45.0\%), 13/20 (65.0\%), and $11 / 16(68.8 \%)$.

Conclusions: Overpenetration into the medial and plantar aspect of the second metatarsal or the proximal and plantar aspect of the fourth metatarsal during shaft or proximal osteotomy could easily damage the deep plantar arch. Shaft or proximal osteotomy approximately $45-47 \mathrm{~mm}$ proximal to the distal epiphysis or $18-23 \mathrm{~mm}$ distal to the tarsometatarsal joint on the plantar aspect could interrupt blood flow in the deep plantar arch.
\end{abstract}

Keywords: Deep plantar arch, Lesser metatarsal, Osteotomy, Cadaveric study

\section{Background}

The deep plantar arch is an important structure because it supplies blood to the plantar metatarsal arteries and subsequently to the metatarsal bases and the toes $[1,2]$. The deep plantar arch is formed by union of the lateral plantar artery and the deep plantar artery [3-7]. In most feet, the main component of the deep plantar arch is an anastomosis between the deep plantar artery

\footnotetext{
* Correspondence: i.tonogai@tokushima-u.ac.jp

${ }^{1}$ Department of Orthopedics, Institute of Biomedical Science, Tokushima University Graduate School, 3-18-15 Kuramoto, Tokushima 770-8503, Japan Full list of author information is available at the end of the article
}

as it passes into the first intermetatarsal space and the dorsalis pedis artery [5].

Osteotomies of the lesser (second, third, and fourth) metatarsals are used to treat various pathologies, including metatarsalgia and metatarsophalangeal subluxation or dislocation [8]. Many osteotomy techniques have been developed to shorten or elevate the lesser metatarsals, including shaft osteotomy [9-12] and proximal metatarsal osteotomy [13, 14]. The shaft osteotomy method allows shortening and subsequent elevation of the metatarsal head by declination while avoiding cock-up toe deformity [8]. Proximal metatarsal osteotomies are very effective for

(C) The Author(s). 2018 Open Access This article is distributed under the terms of the Creative Commons Attribution 4.0 International License (http://creativecommons.org/licenses/by/4.0/), which permits unrestricted use, distribution, and 
correcting forefoot deformities because they allow precise control of the shortening and elevation of the metatarsal head $[15,16]$. However, surgery that involves the lesser metatarsals can lead to iatrogenic disruption of the blood supply to the metatarsals and adjacent structures [17].

There are some reports showing that the distance between the deep plantar arch and each interdigital commissure is generally constant at around $29 \%$ of the total foot length [6, 7]. However, there has been no fresh cadaveric study analyzing the distance between the deep plantar arch and the second, third, and fourth metatarsals.

The aims of this study were to assess the distance between the plantar arch and each of the three lesser metatarsals in fresh cadavers on axial and sagittal enhanced computed tomography $(\mathrm{CT})$ images and to identify factors that could help to prevent injury to the deep plantar arch during osteotomy involving the lesser metatarsals.

\section{Methods}

The study was approved by our institutional review board and included $20 \mathrm{ft}$ of 20 fresh cadavers (10 male, 10 female; mean age 78.6 [48-100] years at the time of death). Cadavers with a history or signs of previous ankle trauma or surgery, congenital or developmental deformity, or inflammatory arthritis were excluded.

The vessels were flushed with warm normal saline solution through a plastic catheter placed in the external iliac artery. Next, barium sulfate suspension (Barytester ${ }^{\circ}$, Fushimi Pharmaceutical Co., Inc., Marugame, Japan) was injected into the external iliac artery with firm manual pressure, as described in our previous report [18-21]. Enhanced multi-slice CT images (Somatom Emotion 16, Siemens Healthcare, Erlangen, Germany) of the lower extremities were obtained in 1.0-mm-thick axial slices. We confirmed the presence of the deep plantar arch on three-dimensional (Fig. 1a) and coronal (Fig. 1b) images. The coronal and axial images were reviewed at bone window setting (window, 2200; level, 200). One specimen was dissected to observe the deep plantar arch (Fig. 2).

The following parameters were measured: (1) the shortest distance from the dorsal aspect of the deep plantar arch to the plantar aspect of the second, third, and fourth metatarsals in the axial plane (Fig. 3a); (2) the shortest distance from the distal epiphysis to a line passing through the deep plantar arch perpendicular to the longitudinal axis of the lesser metatarsal in the sagittal plane (Fig. 3b); and (3) the shortest distance from the tarsometatarsal (TMT) joint to a line passing through the deep plantar arch perpendicular to the longitudinal axis of the lesser metatarsal in the sagittal plane (Fig. 3b). All measurements were made in triplicate by two orthopedic surgeons working independently while blinded to the purpose of the study. The values were averaged and are shown as the mean \pm standard deviation.

\section{Results}

A summary of the results is shown in Table 1. Diagrammatic representations are also shown (Fig. $4 \mathrm{a}-\mathrm{C}$ ). The deep plantar arch was present in all feet. However, in 4 $(20 \%)$ of the 20 specimens, the lateral portion of the
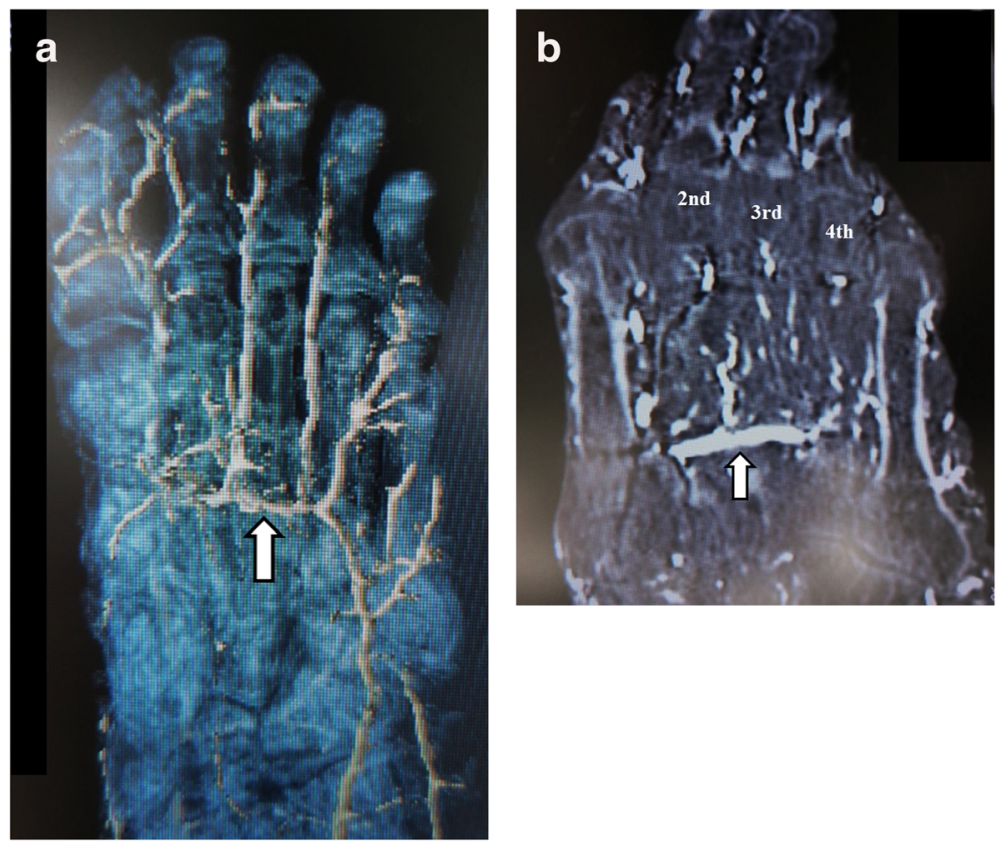

Fig. 1 CT images showing continuity of the deep plantar arch under the lesser metatarsals. a A three-dimensional enhanced CT image viewed from the plantar aspect. b An enhanced CT image in the coronal plane (b). The deep plantar arch is indicated by the arrow. $C$, computed tomography 


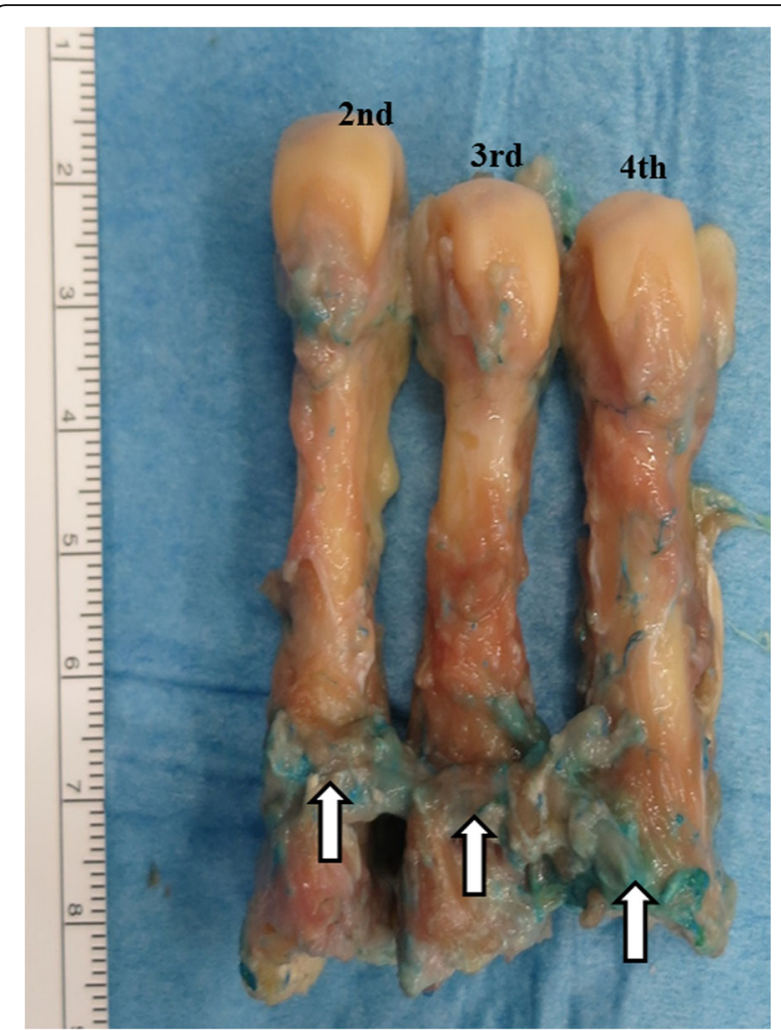

Fig. 2 Photograph showing the dissected deep plantar arch and lesser metatarsals from the plantar aspect. The deep plantar arch is indicated by the arrow

deep plantar arch ran along the longitudinal axis of the fourth metatarsal, so it was impossible to measure the distance from the deep plantar arch to the metatarsal in these cases.

The mean shortest distance from the dorsal aspect of the deep plantar arch to the plantar aspect of the second, third, and fourth metatarsals in the axial plane (1) was $0.5 \pm 0.7$ (range $0-2.7$ ) $\mathrm{mm}, 2.2 \pm 1.5(0-3.7) \mathrm{mm}$, and $2.8 \pm 1.8(0-4.9) \mathrm{mm}$, respectively (Fig. 4a). The shortest distance from the distal epiphysis to a line passing through the deep plantar arch perpendicular to the longitudinal axes of the second, third, and fourth metatarsals in the sagittal plane (2) was $47.0 \pm 3.6$ (range 43-57) $\mathrm{mm}$, $45.7 \pm 3.8(40-53) \mathrm{mm}$, and $46.4 \pm 4.3(39-53) \mathrm{mm}$, respectively (Fig. 4b). The shortest distance from the TMT joint to a line passing through the deep plantar arch perpendicular to the longitudinal axis of the lesser metatarsal in the sagittal plane (3) was $23.0 \pm 3.4$ (range 18-36) mm, $21.0 \pm 3.3(14-27) \mathrm{mm}$, and $18.6 \pm 4.1(13-27) \mathrm{mm}$, respectively (Fig. 4b).

The deep plantar arch ran at the level of the middle third, being in the proximal portion of this third in $11 / 20$ (55.0\%), $7 / 20$ (35.0\%), and 5/16 (31.2\%) of the second, third, and fourth metatarsals, respectively, and at the level of the proximal third in $9 / 20$ (45.0\%), $13 / 20$ (65.0\%), and 11/16 (68.8\%; Fig. 4c).

\section{Discussion}

This report demonstrates that the deep plantar arch runs at the proximal portion of the middle third or proximal third of the second, third, and fourth metatarsals and shows the distance from the deep plantar arch to each of the metatarsals as measured on enhanced axial and sagittal CT images. To our knowledge, this is the first study in which enhanced $\mathrm{CT}$ has been used to measure the distance from the deep plantar arch to each of the three lesser metatarsals in fresh cadaveric feet.

In this study, the shortest distance from the deep plantar arch to the second, third, and fourth metatarsals in the axial plane was $0.5 \mathrm{~mm}, 2.2 \mathrm{~mm}$, and $2.8 \mathrm{~mm}$, respectively. Other reports have focused on the deep plantar artery, which is the deep branch of the dorsalis pedis artery [17, 22]. Consistent with the findings of those studies, we found that the deep plantar artery ran close to the medial side of the second metatarsal and connected with the dorsalis pedis artery to form the deep plantar arch. We found that the deep plantar arch was in contact with the second metatarsal in $12(60.0 \%)$ of 20 cases. Therefore, overpenetration into the medial or plantar aspect of the second metatarsal during shaft or proximal osteotomy might easily damage the deep plantar arch. The lateral part of the plantar arch was running along the longitudinal axis of the fourth metatarsal in 4 (20.0\%) of 20 cases. Therefore, overpenetration into the proximal or plantar aspect during shaft or proximal osteotomy of the fourth metatarsal might also easily damage the deep plantar arch.

In this study, the shortest distance from the distal epiphysis to a line passing through the deep plantar arch perpendicular to the longitudinal axis of the second, third, and fourth metatarsals in the sagittal plane was $47.0 \mathrm{~mm}$, $45.7 \mathrm{~mm}$, and $46.4 \mathrm{~mm}$, respectively. The shortest distance from the TMT joint to a line passing through the deep plantar arch perpendicular to the longitudinal axis of the lesser metatarsal in the sagittal plane was $23.0 \mathrm{~mm}$, $21.0 \mathrm{~mm}$, and $18.6 \mathrm{~mm}$, respectively. This suggests that shaft or proximal osteotomy approximately 45-47 $\mathrm{mm}$ proximal to the distal epiphysis or $18-23 \mathrm{~mm}$ distal to the proximal epiphysis on the plantar side may also interrupt blood flow in the deep plantar arch.

In this study, although the deep plantar arch ran at the level of the middle third of the lesser metatarsals in some specimens (second, 55.0\%; third, 35.0\%; fourth, $31.2 \%)$, the level was in the proximal part of this third in some cases. In contrast, Gabrielli et al. reported that the deep plantar arch was located in the middle third of the foot in all their specimens and in the distal part of this third in $90 \%$ of cases [6]. In another study, Ozer et al. 

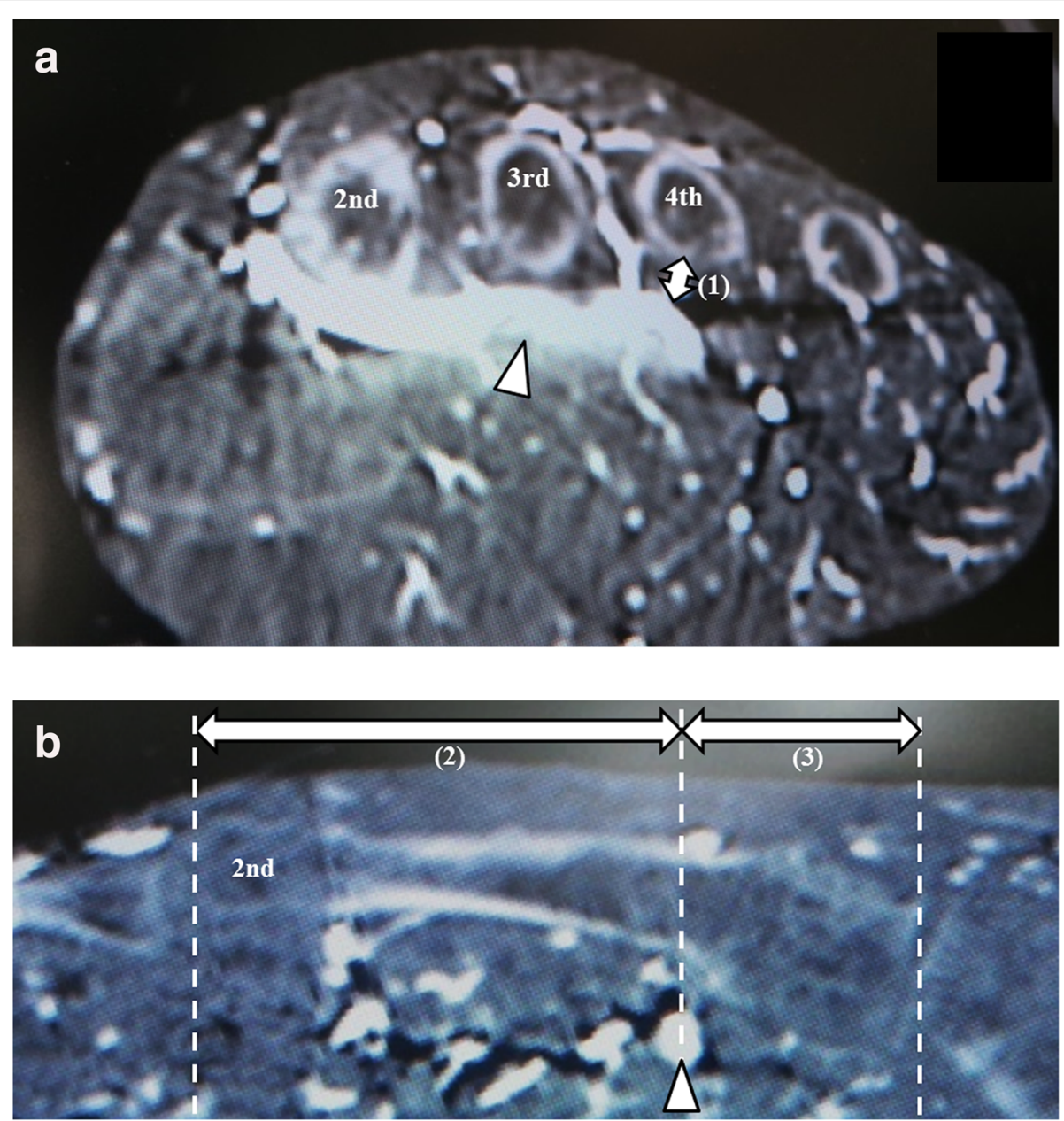

Fig. 3 Enhanced CT images showing the following three parameters. (1) The shortest distance from the dorsal aspect of the deep plantar arch to the plantar aspect of the second, third, and fourth metatarsals in the axial plane. (2) The nearest distance from the distal epiphysis to the line passing the deep plantar arch that was perpendicular to the longitudinal axis of the lesser metatarsal in the sagittal plane. (3) The shortest distance from the tarsometatarsal joint to the line passing the deep plantar arch that was perpendicular to the longitudinal axis of the lesser metatarsal in the sagittal plane. The arrow head indicates the deep plantar arch

found that the deep plantar arch was located in the middle third of the foot in all their specimens and in the middle second part of this third in 62\% [7]. Our findings in this regard are not consistent with those of the earlier studies. Although this discrepancy could reflect ethnic differences in foot and ankle anatomy, we believe that the results of enhanced CT examinations performed in fresh cadavers in our study would be closer to those in the living body than those in dissected formalin-fixed tissue.

Pseudoaneurysm is recognized as a clinically important complication after foot surgery [23]. Although pseudoaneurysm of the lateral or medial plantar artery has been reported following surgical procedures involving the foot, such as pin replacement [24, 25], plantar fasciotomy [26, 27], and endoscopy [27, 28], our findings indicate that metatarsal-cuneiform osteotomies close to the TMT joint put the deep plantar arch at risk of pseudoaneurysm, which could rupture because of the ongoing trauma to the damaged artery during ambulation [29]. Therefore, the clinical significance of our findings may be that foot surgery should be performed carefully to prevent pseudoaneurysm caused by injury to the deep plantar arch.

This study has several limitations, in particular the small number of specimens used, which is inevitable given the restricted availability of fresh-frozen cadavers in Japan. Another limitation is the lack of examination of the vessels contributing to the deep plantar arch. Other authors have reported that the arterial components of the deep plantar arch can be classified as a predominantly dorsalis pedis type of artery, a predominantly lateral type of plantar artery, or a balanced type according to the dominant contributing artery [30-32]. Further investigations are needed to determine the contributions of the deep plantar arch to the results of this study. 


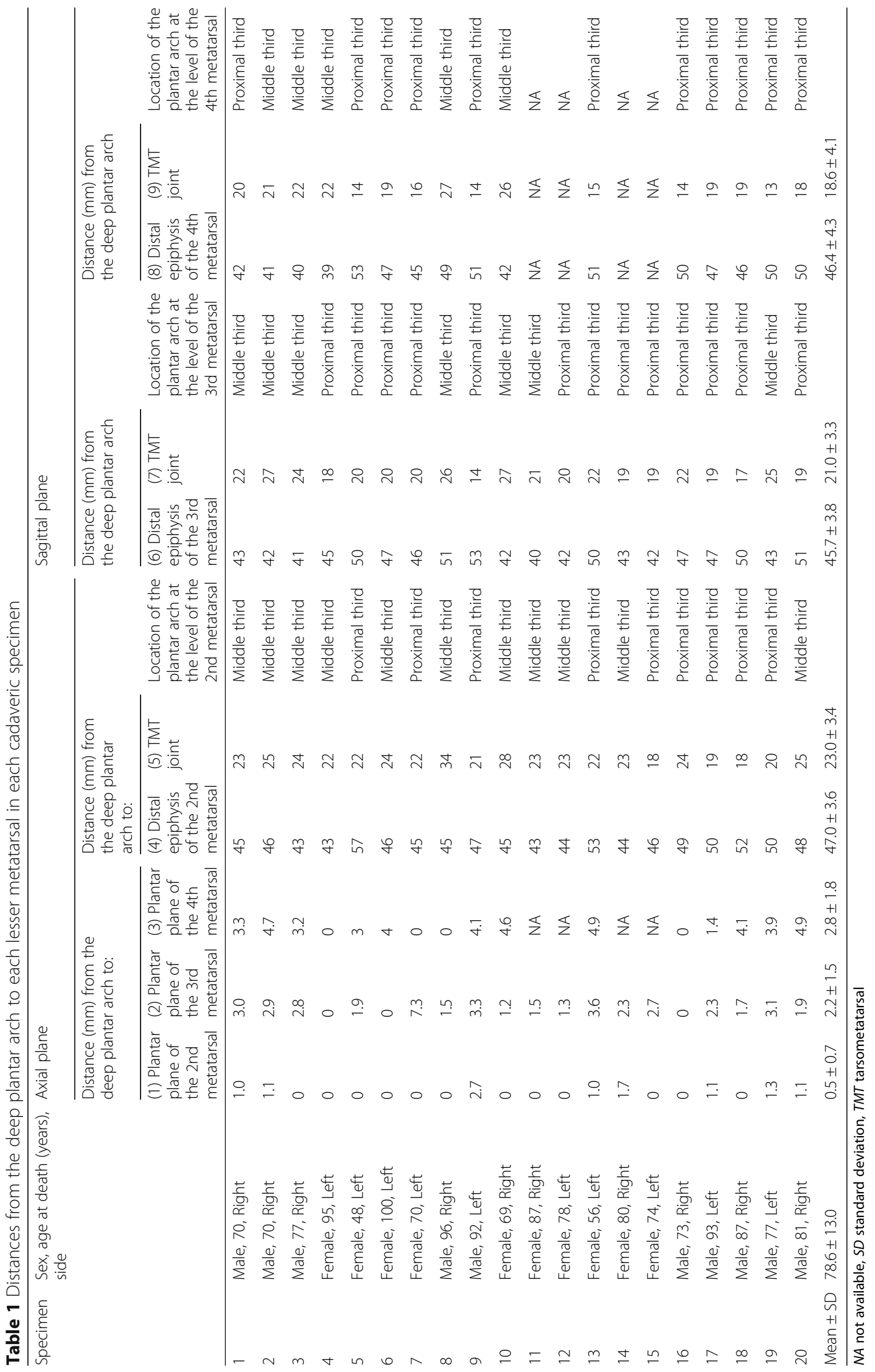



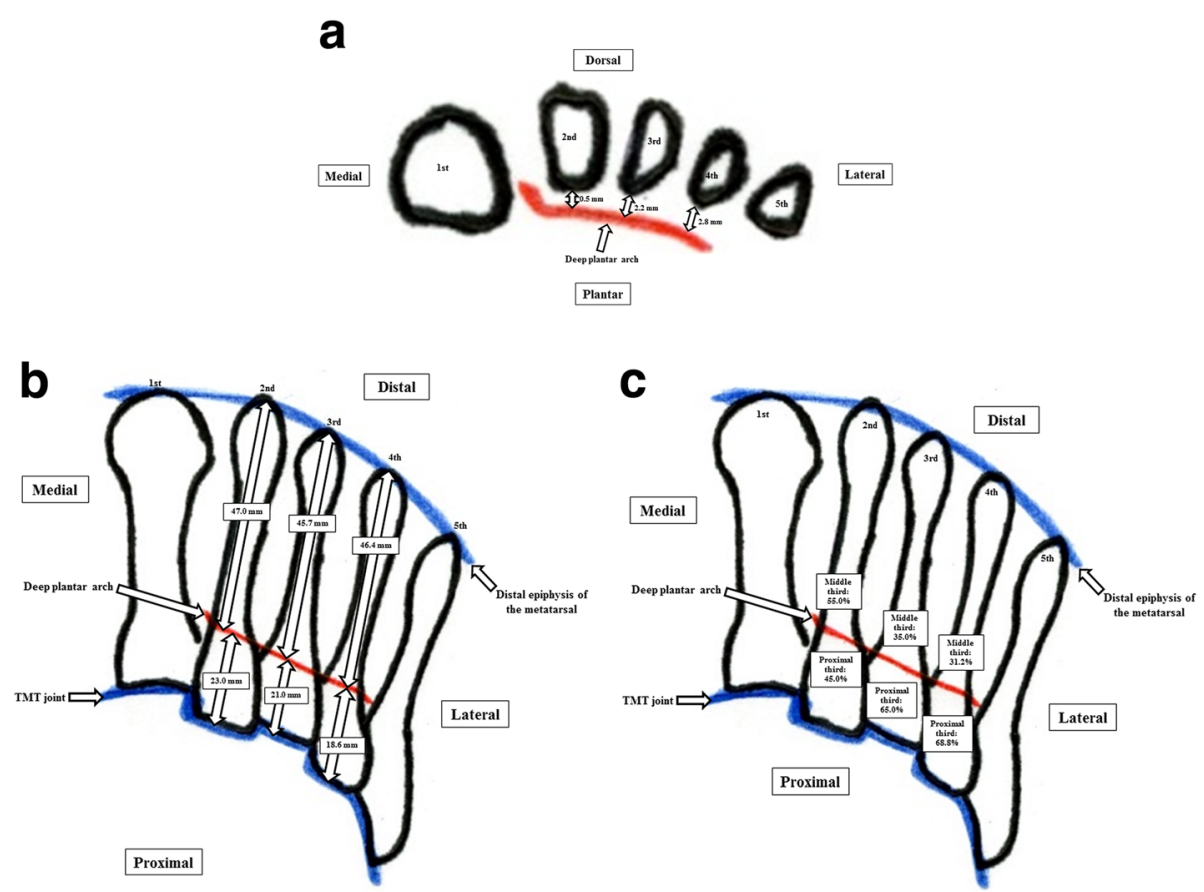

Fig. 4 Diagram showing distances from the deep plantar arch to the lesser metatarsals. a Measurements on axial images. a Distance from the deep plantar arch to each distal epiphysis of the lesser metatarsal and TMT joint. b The running level of the deep plantar arch (c). TMT, tarsometatars

\section{Conclusions}

This study shows that the deep plantar arch runs in the proximal portion of the middle third or proximal third of the second, third, and fourth metatarsals. It also revealed the distance from the deep plantar arch to each of the three lesser metatarsals on axial and sagittal enhanced CT images. Overpenetration into the medial and plantar aspects of the second metatarsal or into the proximal and plantar aspects of the fourth metatarsal during shaft or proximal osteotomy could easily damage the deep plantar arch. Shaft or proximal osteotomy approximately $45-47 \mathrm{~mm}$ proximal to the distal epiphysis or $18-23 \mathrm{~mm}$ distal to the TMT joint on the plantar side could interrupt blood flow in the deep plantar arch.

\section{Abbreviations \\ CT: Computed tomography; TMT: Tarsometatarsal}

\section{Funding}

This study was supported in part by a Grant-in-Aid for Scientific Research from the Ministry of Education, Culture, Sports, Science and Technology of Japan (17 K16694 to IT). The funding source had no role in the design of the study, in the collection, analysis, or interpretation of data, or in the writing of the manuscript.

\section{Availability of data and materials}

All data generated or analyzed during this study are included in this published article.

\section{Authors' contributions}

IT was responsible for and managed the study. IT performed the enhanced $\mathrm{CT}$ examinations on the cadavers. IT did not results to measurement. FH measured the parameters in the obtained images. YT supervised the enhanced $\mathrm{CT}$ examinations performed on the cadavers by IT. KS also measured the parameters in the obtained images. All authors read and approved the final manuscript.

Ethics approval and consent to participate

This study was approved by the research board of Tokushima University Hospital (reference no. 2258).

\section{Consent for publication}

Not applicable

\section{Competing interests}

The authors declare that they have no competing interests.

\section{Publisher's Note}

Springer Nature remains neutral with regard to jurisdictional claims in published maps and institutional affiliations.

\section{Author details}

'Department of Orthopedics, Institute of Biomedical Science, Tokushima University Graduate School, 3-18-15 Kuramoto, Tokushima 770-8503, Japan. ${ }^{2}$ Department of Anatomy and Cell Biology, Institute of Biomedical Science,

Tokushima University Graduate School, 3-18-15 Kuramoto, Tokushima 770-8503, Japan.

Received: 31 July 2018 Accepted: 7 October 2018

Published online: 16 October 2018

\section{References}

1. Yamada T, Gloviczki P, Bower TC, Naessens JM, Carmichael SW. Variations of the arterial anatomy of the foot. Am J Surg. 1993;166:130-5.

2. Rath B, Notermans HP, Franzen J, Knifka J, Walpert J, Frank D, Koebke J. The microvascular anatomy of the metatarsal bones: a plastination study. Surg Radiol Anat. 2009;31:271-7.

3. Hamada N, Ikuta Y, Ikeda A. Arteries to the great and second toes based on three-dimensional analysis of 100 cadaveric feet. Surg Radiol Anat. 1993;15: 187-92. 
4. Hamada N, Ikuta Y, Ikeda A. Arteriographic study of the arterial supply of the foot in one hundred cadaver feet. Acta Anatom. 1994;151:198-206.

5. Papon X, Brillu C, Fournier HD, Hentati N, Mercier P. Anatomic study of the deep plantar artery: potential by-pass receptor site. Surg Radiol Anat. 1998; 20:263-6.

6. Gabrielli C, Olave E, Mandiola E, Rodrigues CF, Prates JC. The deep plantar arch in humans: constitution and topography. Surg Radiol Anat. 2001;23:253-8.

7. Ozer MA, Govsa F, Bilge O. Anatomic study of the deep plantar arch. Clin Anat. 2005;18:434-42.

8. DeSandis B, Ellis SJ, Levitsky M, O'Malley Q, Konin G, O'Malley MJ. Rate of union after segmental midshaft shortening osteotomy of the lesser metatarsals. Foot Ankle Int. 2015;36:1190-5.

9. Helal B. Metatarsal osteotomy for metatarsalgia. J Bone Joint Surg Br. 1975; 57:187-92.

10. Helal B, Griess M. Telescoping osteotomy for pressure metatarsalgia. J Bone Joint Surg Br. 1984;66:213-7.

11. Spence KF, O'Connell SJ, Kenzora JE. Proximal metatarsal segmental resection: a treatment for intractable plantar keratosis. Orthopedics. 1990;13:741-7.

12. Galluch DB, Bohay DR, Anderson JG. Midshaft metatarsal segmental osteotomy with open reduction and internal fixation. Foot Ankle Int. 2007;28:169-74.

13. Harper MC. Dorsal closing wedge metatarsal osteotomy: a trigonometric analysis. Foot Ankle. 1990;10:303-5.

14. Barouk LS. Forefoot reconstruction. 2nd ed. Paris: Springer Verlag; 2005.

15. Pearce CJ, Calder JD. Metatarsalgia: proximal metatarsal osteotomies. Foot Ankle Clin. 2011;16:597-608.

16. Vafek EC, Lee S. Treatment of metatarsalgia with proximal osteotomies. Foot Ankle Clin. 2018;23:35-46.

17. Chuckpaiwong B, Korwutthikulrangsri E. Safety area for proximal metatarsal procedures. Foot Ankle Int. 2013;34:579-81.

18. Tonogai I, Hayashi F, Tsuruo Y, Sairyo K. Direction and location of the nutrient artery to the fifth metatarsal at risk in osteotomy for bunionette. Foot Ankle Surg. 2017. https://doi.org/10.1016/j.fas.2017.10.006.

19. Tonogai I, Wada K, Higashino K, Fukui Y, Sairyo K. Location and direction of the nutrient artery to the first metatarsal at risk in osteotomy for hallux valgus. Foot Ankle Surg. 2017. https://doi.org/10.1016/j.fas.2017.05.004.

20. Tonogai I, Hayashi F, Tsuruo Y, Sairyo K. The distance between the anterior distal tibial edge and the anterior tibial artery in non-distracted and distracted ankle positions during anterior ankle arthroscope: a cadaveric study. Foot Ankle Int. 2018;39:113-8.

21. Tonogai I, Hayashi F, Tsuruo Y, Sairyo K. Examination of the origin and branching direction of the anterior medial malleolar artery from the anterior tibial artery to avoid pseudoaneurysm in anterior ankle arthroscopy: a cadaveric study. Foot Ankle Spec. 2018. doi:https://doi.org/10.1177/ 1938640018768046.

22. Barrett MO, Wade AM, Della Rocca GJ, Crist BD, Anglen JO. The safety of forefoot metatarsal pins in external fixation of the lower extremity. J Bone Joint Surg Am. 2008;90:560-4.

23. Mardjetko SM, Lubicky JP, Kuo KN, Smrcina C. Pseudoaneurysm after foot surgery. J Pediatr Orthop. 1991;11:657-62.

24. Baeza L, Farrell ED, Salgado CJ. Medial plantar artery pseudoaneurysm following percutaneous pinning for Lisfranc fracture-dislocation. J Am Podiatr Med Assoc. 2009;99:58-60.

25. Cabitza P, Zamberletti N, Casana R, Azzoni R. latrogenic arteriovenous fistula after trans-heel traction pin: a case report. J Trauma. 2007;62:1053-5.

26. Nierenberg G, Hoffman A, Engel A, Stein H. Pseudoaneurysm with an arteriovenous fistula of the tibial vessels after plantar fasciotomy: a case report. Foot Ankle Int. 1997;18:524-5.

27. Gentile AT, Zizzo CJ, Dahukey A, Berman SS. Traumatic pseudoaneurysm of the lateral plantar artery after endoscopic plantar fasciotomy. Foot Ankle Int. 1997;18:821-2

28. O'Brien SP, Simoni EJ, Jain KM, Munn JS. Arteriovenous fistula and pseudoaneurysm formation following heel endoscopy. Eur J Vasc Endovasc Surg. 1997:13:240-1.

29. Economou P, Paton R, Galasko CS. Traumatic pseudoaneurysm of the lateral plantar artery in a child. J Pediatr Surg. 1993;28:626.

30. Manno A. Arteriae plantares pedis mammalium. Int Monatsschr Anat Physiol. 1905;22:293-359

31. Adachi B. Das arteriensystem der Japaner. Kyoto: Maruzen; 1928. p. 215-91.

32. Vann MH. A note on the formation of the plantar arterial arch of the human foot. Anat Rec. 1943:85:269-75.

Ready to submit your research? Choose BMC and benefit from:

- fast, convenient online submission

- thorough peer review by experienced researchers in your field

- rapid publication on acceptance

- support for research data, including large and complex data types

- gold Open Access which fosters wider collaboration and increased citations

- maximum visibility for your research: over $100 \mathrm{M}$ website views per year

At BMC, research is always in progress.

Learn more biomedcentral.com/submissions 